\title{
En un lugar del aula... De lo que le sucedió a don Quijote en una clase de E/LE
}

LuZ C. Souto

Universitat de València

luz.souto@uv.es

Resumen: El presente trabajo tiene como objetivo mostrar una vía para la lectura de $E l$ ingenioso hidalgo don Quijote de la Mancha en el aula de E/LE. La propuesta se realizará a través de una selección de recursos y actividades sobre el clásico de Cervantes. Las preguntas desde las cuales se parte para el planteamiento son: ¿Qué es un clásico? ¿Por qué leer a Cervantes en la clase de E/LE? ¿Cómo leerlo? ¿Qué ventajas tiene El Quijote en el siglo XXI para quienes tienen el español como segunda lengua?

Palabras Clave: Siglo de Oro, Quijote, clase de E/LE, literatura

\begin{abstract}
The present work aims to show a way to read El ingenioso hidalgo don Quijote de la Mancha in the E/LE class. The proposal is made through a selection of resources and activities about Cervantes. The questions we ask are: what is a classic? Why read Cervantes in E/LE class? How to read it? What are advantages of El Quijote in the 21st century for those who have Spanish as a second language?
\end{abstract}

Keywords: Spanish Golden Age, Quixote, E/LE class, literature 


\section{Introducción}

Cada vez más los programas de E/LE incluyen en su currículo las obras clásicas del Siglo de Oro, un ítem que, si bien es acertado porque permite el cruce entre la lengua y la cultura, puede llegar a presentar inconvenientes. Algunas de las reticencias para el abordaje en el aula se fundamentan en la distancia cultural que media de la literatura del siglo XVII a la era digital, a esto se suma la dificultad de un español que se expresa con un lenguaje rico en cultismos, neologismos, arcaísmos y un sinfín de figuras retóricas. De modo que no solamente nos enfrentamos al léxico de los escritores áureos, también debemos asumir el desafío de la interpretación. Sin embargo, hay que tener en cuenta que si diseñamos un programa adecuado al nivel, con la cantidad justa de lecturas y lo aderezamos con los ingredientes didácticos adecuados, el resultado puede ser muy satisfactorio, no solamente para los alumnos, también para los profesores.

Si nos centramos en la renovación literaria del Siglo de Oro podemos hacerlo desde tres frentes diferentes: la narrativa, el teatro o la poesía. Ocupar los tres ámbitos no es imposible, pero para hacerlo necesitaríamos un curso entero y aún así los alumnos acabarían extenuados, o leyendo un poco de cada autor y cada género, mezclando nombres, obras y desalentados ante la imposibilidad de asir tantas décadas de lengua, literatura, arte y cultura española. Por eso nuestra propuesta para leer a los clásicos comienza con un recorte, primero en cuanto al género y segundo en cuanto a la nómina de autores. Como puede preverse desde el título, la propuesta de actividades se centrará en la narrativa y dentro de esta en la obra más conocida de Cervantes: El ingenioso hidalgo don Quijote de la Mancha (I, 1605; II, 1615).

Las presentes páginas siguen la fundamentación teórica de otros trabajos ya desarrollados en torno al Quijote, como el de Gracia (2005), en el que se conjuga «la competencia cultural, la competencia discursiva, y la competencia literaria». No obstante, el objetivo de este artículo es hacer hincapié en la vigencia del Quijote en el siglo XXI como texto y como ícono constitutivo de la cultura española. Por eso, además de la lectura, interpretación y trabajo sobre los contenidos discursivos y léxico-gramaticales se proporcionan actividades que posibilitan a los alumnos un aprendizaje activo, en el que puedan integrar el bagaje de cada uno con los nuevos conocimientos. En consecuencia, la opción metodológica seleccionada es un enfoque por tareas, de modo que las actividades que se enunciarán, en tanto tareas posibilitadoras, permitirán una inmersión en la cultura española y, a la vez, un desarrollo progresivo en las destrezas orales y escritas del español. De este modo, los alumnos deberán construir su propio proceso de aprendizaje a partir de la indagación y la reflexión. Igualmente cabe destacar que las situaciones comunicativas que se llevarán a cabo en el aula pueden ser adaptadas a todos los niveles, pero darán muchas más posibilidades de trabajo a partir de un B1. El grado de dificultad puede aumentar, ya que los materiales esgrimidos van desde los más básicos hasta los que necesitan un manejo del español como nativos.

\section{La lectura de los clásicos en la clase de E/LE}

Antes de repasar el material que puede facilitarnos las actividades en el aula quisiéramos introducir dos cuestiones que se consideran clave para la impartición del Siglo de Oro. La primera de ellas es ¿qué es un clásico? ¿Por qué estudiar a los clásicos en la clase de E/LE? La segunda, derivada de la primera, ¿desde dónde leer a los clásicos? 
De este modo, las primeras actividades del programa estarán destinadas a preparar a los alumnos, cual Alonso Quijano con su Rocinante, para emprender el camino de los clásicos, saber qué opción escoger en cada encrucijada léxica, sobrevivir a la polvareda de arcaísmo que arrastran los ejércitos de ovejas, y no ser ingenuos ante las carretas de «Las cortes de la muerte» (II, 11) que, cargadas de farsantes, nos atemorizan al cruzar la frontera de la lectura y la comprensión.

Para la resolución de estas dos preguntas introductorias, además de recurrir a la RAE, que nos lleva a interpretar el sentido primero de la voz clásico $^{1}$, se recomienda comenzar con la introducción de Calvino (1992), donde propone catorce definiciones que permiten vislumbrar el alcance de estas lecturas. Solo se mencionan cinco de ellos, que ayudan a imaginar el proceso de intercambio con los alumnos.

Con el primer ítem el autor nos ayuda a entrar en los clásicos olvidándonos de los reparos por todo aquello que no se ha leído: «Los clásicos son esos libros de los cuales se suele oír decir: "Estoy releyendo..." y nunca "Estoy leyendo ...”» (1992: 13). Esta primera aproximación permitirá saber que siempre es un buen momento para introducirnos en el Siglo de Oro. La tercera propuesta de Calvino es «Los clásicos son libros que ejercen una influencia particular ya sea cuando se imponen por inolvidables, ya sea cuando se esconden en los pliegues de la memoria mimetizándose con el inconsciente colectivo o individual» (1992: 14). El sexto axioma: «Un clásico es un libro que nunca termina de decir lo que tiene que decir» (1992: 15), el undécimo: «Tu clásico es aquel que no puede serte indiferente y que te sirve para definirte a ti mismo en relación y quizás en contraste con él». Finalmente, el décimo cuarto acercamiento: «Es clásico lo que persiste como ruido de fondo incluso allí donde la actualidad más incompatible se impone» (1992: 19).

La primera actividad estará ligada a la interiorización de la noción de clásico a partir de los conocimientos previos. Así, el profesor planteará una discusión en la que se evaluará la expresión oral y escrita de los integrantes del grupo.

Actividad 1. Todos los niveles.

A partir de estas definiciones pediremos a los alumnos que enumeren sus propios clásicos y que indiquen por qué los consideran importantes en su vida. La pregunta también puede ser trasladada a los clásicos del cine, las series o la música. Esta actividad es de carácter introductorio y nos permitirá evaluar el nivel real de español de los estudiantes.

Asimismo, el objetivo de esta primera aproximación es dejar claro que, para adentrarnos en el Quijote no es necesario ser un especialista en Siglo de Oro, ni tener un vocabulario exquisito. Los clásicos se denominan así porque nos interpelan a partir de problemas que sucedieron en los siglos XVII, en el XVIII, el XIX, en el XX, e incluso en el siglo XXI. Por otro lado, la cultura actual no ha dejado de recuperarlos desde diferentes puntos de vista y formatos. La consigna «leer a Cervantes desde el siglo XXI» permitirá a los estudiantes

\footnotetext{
${ }^{1}$ Para la RAE clásico es «Período de tiempo: De mayor plenitud de una cultura / 2. Dicho de un autor, de una obra, de un género, etc.: Que pertenece al período clásico. Apl. a un autor o a una obra. 3. adj. Dicho de un autor o de una obra: Que se tiene por modelo digno de imitación en cualquier arte o ciencia. 4. adj. Perteneciente o relativo al momento histórico de una ciencia en el que se establecen teorías y modelos que son la base de su desarrollo posterior». Se trata de explicar a los estudiantes que el Siglo de Oro ha sentado las bases de la literatura española y latinoamericana.
} 
de E/LE una experiencia personal, sentir que también contribuyen a la interpretación y que adquirirán nuevos vocablos y estructuras gramaticales y profundizarán en la cultura española. No hay mejor manera de trasmitir los clásicos que acompañando a los estudiantes para que tengan un contacto único con lo que aprendan. Eso se consigue presentándoles actividades que, primero, los hagan sentir activos; segundo, los estimulen a una lectura igualmente activa. Nuestra misión es acompañarles en el salto a los clásicos del Siglo de Oro y guiarles para que sepan cómo leerlos, ya que, como asevera Vázquez Montalbán: «Yo soy responsable de lo que he escrito, pero tú eres [...] responsable de lo que has leído» (Hart, 1987: 100). A esto podemos agregar que, como profesores de E/LE, somos responsables de cómo enseñamos a leer.

\section{3. ¿Cómo presentar a Miguel de Cervantes?}

Actividad 2. Todos los niveles.

Para sumergirnos en el mundo cervantino se propone una actividad que mantendrá alerta a los alumnos durante todo el curso: la búsqueda de productos culturales actuales que hagan referencia a Miguel de Cervantes y a sus personajes, especialmente a don Quijote, a Sancho Panza y a Dulcinea. En la tarea de recopilación de datos los estudiantes podrán aportar desde películas y series hasta cómics, pinturas, ilustraciones, arte urbano, videojuegos, canciones, etc. El objetivo es que aprecien el vigor cultural y que compartan la experiencia a partir de un lenguaje asequible en los niveles más bajo y con un trabajo sobre la argumentación en los niveles más avanzados. Al comienzo de cada clase se dedicarán unos minutos para que los alumnos describan oralmente lo que han encontrado. Con el fin de alentar la mirada crítica proponemos una serie de preguntas: ¿Cómo recuperan a don Quijote esos productos culturales?, ¿qué aventuras son recobradas?, ¿qué efecto tiene en el público?, ¿nos interesa la nueva manera de entender la obra de Cervantes?, ¿cuáles son las ventajas y desventajas?

Actividad 3. Todos los niveles.

Una buena introducción al autor es la falta de registro sobre su semblante. Partiremos de dos cuadros, uno del siglo XXI, del valenciano Alejandro Cabeza, y el otro del XVIII, de Manuel Salvador Carmona. La pregunta que abrirá el debate es ¿Cuál de los dos retratos se aproxima más al escritor?
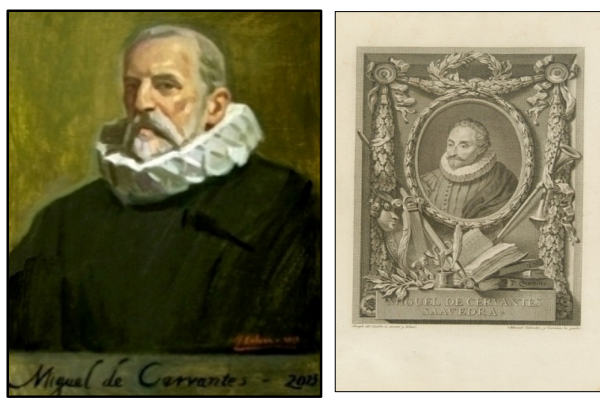

Imágenes 1 y 2. Retratos de Miguel de Cervantes de A. Cabeza (2015) ${ }^{2}$ y M. Salvador Carmona (1780) ${ }^{3}$

2 El cuadro se encuentra actualmente en el Museo de Historia de Madrid. Recuperada de http://www.alejandrocabeza.net/search/label/Miguel\%20de\%20Cervantes

${ }^{3}$ http://www.csdl.tamu.edu:8080/DQIIMAGES/largeimages/39/1780-Madrid-Ibarra-01-002-p.jpg 
Con el objetivo de valorar el nivel de español de los estudiantes, todos deberán justificar su opinión por escrito y luego leerla al resto de la clase. Lo más usual es que seleccionen el retrato de Salvador Carmona como el más exacto, por el simple hecho de la cercanía temporal. Sin embargo, en el caso de Cervantes no hay pinturas realizadas en vida que den cuenta de sus características físicas. Por ello, las dos caracterizaciones son válidas, incluso, la de Alejandro Cabeza ha tenido más posibilidades documentales.

Actividad 4. Todos los niveles.

Una vez que el grupo esté introducido en el misterio de la imagen del escritor continuaremos con algunos rasgos biográficos. Un recurso interesante para indagar en su vida es proponer a los estudiantes que expongan diferentes facetas del autor a partir de las fichas del Centro Virtual Cervantes ${ }^{4}$. Aquí encontraremos dibujos acompañados de oraciones breves, con un vocabulario accesible y que proporcionan datos sobre la familia, la sociedad, el amor, la educación, el dinero, la religión, su trabajo como escritor, la batalla de Lepanto, su paso por las prisiones de Argel, etc. En este punto se puede trabajar la expresión oral y escrita, sin entrar aún en la comprensión textual.

\section{Leer un clásico español: el Quijote}

Y ya entrando en la obra más conocida de Cervantes comenzaremos por mostrar cómo fue la primera edición de la novela. Actualmente la Biblioteca Nacional tiene una versión interactiva de la edición príncipe ${ }^{5}$, por lo que podemos realizar una rápida navegación que ilustre las publicaciones del siglo XVII.

Para introducirnos en la lectura del texto primero debemos advertir a los estudiantes sobre las trampas que pone el autor, ya que los diversos narradores de la novela pueden significar una dificultad añadida ${ }^{6}$. Una vez más la imagen puede sernos de ayuda para mostrar la posición de Cervantes en su Quijote. De modo que, para ejemplificar el punto de vista del Barroco acudiremos a un cuadro que seguramente ya conocerán, se trata de Las meninas de Diego Velázquez. Gamerro asevera que «Los procedimientos pictóricos de Velázquez en Las meninas se parecen hasta tal punto a los ya descritos por Cervantes, que puede afirmarse, sin temor a exagerar, que el Quijote y Las meninas son, esencialmente, la misma obra realizada en diferentes medios» (2010: 26).

\footnotetext{
${ }^{4}$ http://cvc.cervantes.es/artes/menc/facetas.htm

${ }^{5}$ http://quijote.bne.es/libro.html

${ }^{6}$ Para una aproximación a los diversos narradores del Quijote véase Maestro (2001). En este estudio Maestro identifica los siguientes niveles. Primero, el autor real: Miguel de Cervantes. Segundo, cinco autores ficcionales: 1. Autor primero: Anónimo (Caps. 1-8). 2. Cronista: Cide Hamete Benengeli (Cap. 9 en adelante) 3. El traductor morisco. 4. Los académicos de Argamasilla, autores de los poemas donados al narrador por "un antiguo médico que tenía en su poder una caja de plomo, que, según él dijo, se había hallado en los cimientos derribados de una antigua ermita que se renovaba..." (I, 52). 5. Un narrador anónimo que organiza, prologa y edita el texto completo.
} 


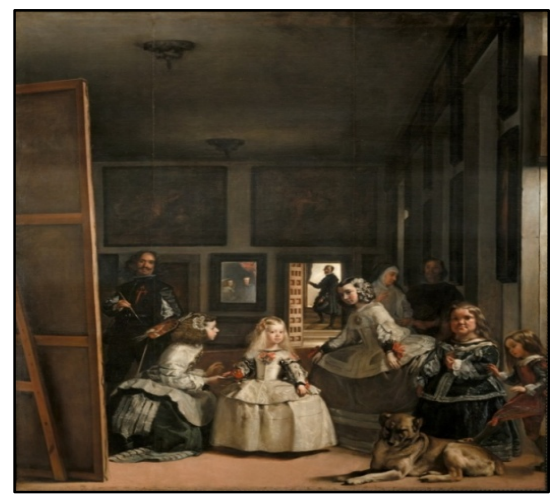

Imagen 3. Las meninas / La familia de Felipe IV de Diego Velázquez (1656) ${ }^{7}$

Cervantes, como Velázquez en su cuadro, estructura una novela en que todo es absorbido por el mundo de la ficción. El autor mismo se convertirá en personaje, incluso los personajes de ficción de la Primera Parte, en la Segunda Parte ya han leído el Quijote. El juego entre narradores-autor, realidad-ficción, locura-cordura es continuo. Esta es una de las estrategias narrativas más espectaculares de Cervantes y muchas veces su importancia se pierde tras la historia lineal de Alonso Quijano enloquecido por los libros de caballería. Para interiorizar el punto de vista se propone un juego de roles con los alumnos. Cada uno deberá elegir un personaje del cuadro de Velázquez e interpretarlo. A continuación se les dejará 15 minutos para que apunten las sensaciones principales a partir de imaginar qué ven, qué oyen y qué huelen. Finalmente representarán frente a la clase el personaje seleccionado.

\section{1. ¿Cómo organizar la lectura de don Quijote?}

A la hora de emprender el viaje a través de los capítulos del Quijote deberemos tener en cuenta el nivel al que nos dirigimos y el tiempo que podemos destinar a la lectura. Si se trata de los niveles B2, C1 y C2 se recomienda trabajar con ediciones como la de Andrés Murillo de la editorial Castalia, ya que además de tener una edición fiable contaremos con notas orientativas que facilitarán la lectura. Si no disponemos de un curso completo lo mejor es hacer una selección de capítulos teniendo en cuenta las tres salidas de Alonso Quijano ${ }^{8}$ :

\section{Primera salida $\rightarrow$ Primera Parte, capítulos 1-6 \\ Segunda salida $\rightarrow$ Primera Parte, capítulos 7-52 \\ Tercera salida $\rightarrow$ Segunda Parte, capítulos 1-74}

En el caso de los niveles iniciales A2, o incluso B1, se recomienda comenzar por una edición modernizada. Como apoyo complementario se detallarán a continuación algunos de los métodos que nos facilitarán el acercamiento a la trama y a los personajes de Cervantes.

\footnotetext{
${ }^{7}$ Recuperada de https://www.museodelprado.es/coleccion/obra-de-arte/las-meninas/9fdc7800-9ade-48b0ab8b-edee94ea877f

${ }^{8}$ Para una guía de los principales capítulos organizada por las respectivas salidas véase Riquer (1970).
} 


\subsection{El Quijote en el siglo XX y XXI}

La producción cultural en torno a la obra de Cervantes es muy abundante, lo cual supone una ventaja en el momento de preparar las clases y, sobre todo, un hándicap para despertar el interés de los estudiantes.

Actividad 5. Todos los niveles.

Esta propuesta tiene como objetivo la inmersión del grupo en el mundo de Cervantes y de su Quijote. En cada viaje que realicen deberán fotografiar el rastro de Cervantes, ya sea en estatuas, esculturas, nombres de calles, nombres de parques, sellos de correo, postales, etc. La búsqueda de Cervantes y sus personajes en el espacio público les permitirá conocer la magnitud del autor y de su obra, además de que los motivará para sentirse partícipes del universo literario aunque tengan un nivel de español básico. Hacia el final del curso deberán hacer una exposición oral, mostrando las fotos realizadas y seleccionando y explicando un capítulo de la novela que deberá estar relacionado con la imagen conseguida.

Actividad 6. Todos los niveles.

Dado que Quijote es uno de los clásicos que más ha influido en la cultura contemporánea también existen muchísimas apropiaciones pictóricas ${ }^{9}$. Así, cuando se lean los capítulos seleccionados, estos pueden ilustrarse con pinturas o cuadros de artistas reconocidos. Un ejemplo que suele atraer a los estudiantes es el de Salvador Dalí. En este caso, cada vez que se lea y explique un capítulo, en clase y con la guía del profesor, se solicitará a los alumnos que señalen las características que ven en la pintura y que respondan oralmente a los siguientes interrogantes: ¿Cómo se relaciona la representación que diseña Salvador Dalí con lo leído en la novela? ¿Por qué creen que la figura de Quijote ha captado la atención de Dalí? ¿Qué aspecto de Quijote le atrae más al pintor? ¿Qué divergencias hay entre el Quijote de Cervantes y el Dalí? ¿Qué características del Quijote de Cervantes y/o de Dalí os interesan más?

A continuación, los estudiantes de los niveles $\mathrm{B} 1$ a C2 deberán hacer una descripción, por escrito, del cuadro y de las semejanzas y diferencias con el fragmento leído de la novela. Para los niveles A1-A2 se puede solicitar dos listados, primero, uno de palabras o frases que describan las imágenes; segundo, apuntar y discutir con el profesor las palabras o frases que presenten más dificultad de los fragmentos leídos.

Actividad 7. Todos los niveles.

Esta tarea tendrá como elementos principales las adaptaciones en cómic de la obra de Cervantes. La importancia de las viñetas en el aula para trasmitir temas de envergadura o para impartir conocimientos con distintos niveles de aprendizaje ya ha sido ampliamente estudiada, así, se han aproximado a este terreno, entre otros, Barrero (2002), Silva-Díaz (2009), Burgos (2016), Sebastián-Fabuel (2016). En el caso específico de la enseñanza de E/LE por medio del cómic pueden consultarse trabajos como los de Catalá (2007), Villarrubia (2009), Alonso (2012), García (2013) o Battagliero (2016).

\footnotetext{
${ }^{9}$ Representaciones iconográficas de don Quijote: http://www.fundaciondoctordepando.com/
} 
Respecto a la recuperación de don Quijote en las viñetas hay un minucioso y crítico trabajo en donde se efectúa un recorrido por las adaptaciones, aunque, advierte de la traición que esto supone a la obra de Cervantes:

Esta representación que se ofrece en el cómic impide y bloquea la posibilidad de que el lector recree virtualmente la obra, ya que la formulación específica que tiene en las manos y que visualiza/lee impone su sistema de signos representativos y anula cualquier posibilidad de imaginar la historia de otra forma en el acto de la lectura. Y tanto da que el cómic sea bueno o malo en tanto que medio, ya que entonces hablaremos de una buena o de una mala adaptación pero nunca de un Quijote auténtico.

A. Martín (2004: 47)

Realizada esta salvedad, consideramos que para los alumnos que están en el proceso de aprehensión del español y de los clásicos castellanos, introducirse en el mundo de Cervantes desde el cómic puede significar el primer contacto con los personajes, el universo social y el conflicto, de un modo cercano y con un lenguaje asequible. Para el listado de adaptaciones de Don Quijote entre 1940 y 2003, que tienen entidad editorial y título propio, se recomienda el estudio de Martín (2004) y el proyecto Iconografía popular de don Quijote, realizado por la Universidad de Castilla-La Mancha, en el que se recogen viñetas desde el siglo XIX hasta el año 2005. Se suman a los tebeos litografías, grabados y álbumes de cromos, desde el siglo XVII hasta el XX.

Nuestra propuesta para el aula será a partir de adaptaciones recientes que no están aún catalogadas en los trabajos mencionados, como es el caso de Cervantes: la ensoñación de un genio de Gol (2015) y los Don Quijote de Flix (2014) y de Davis (2013) ${ }^{10}$. En el caso de estos dos últimos libros interesa marcar la singularidad e internacionalidad, ya que se trata de autores extranjeros, un alemán y un británico, que actualizan e ilustran la obra de Cervantes. El primero de ellos, Flix (Felix Görmann), recrea a un anciano y malhumorado Alonso Quijano con problemas y molinos del siglo XXI. El lugar de la acción no será en territorio español sino en un ficticio pueblo alemán: Tobosow. Allí, nuestro héroe intemporal se enfrentará a una planta de molinos de energía eólica y emprenderá diferentes acciones reivindicativas, algo que aprovecha Flix para plasmar su visión crítica de la sociedad actual. Así, las vicisitudes de la vida moderna se intercalan en la acción: la hija de Quijano es divorciada y debe hacerse cargo de su hijo (Robin/ Sancho) y de su padre con demencia senil. Abuelo y nieto se suben a la aventura a lomos de una bicicleta. Por supuesto, esta versión no busca fidelidad a la obra sino recuperar sus conflictos principales y dar cuenta de la vigencia e internacionalidad del clásico.

En el caso del británico Rob Davis, su obra está considerada una de las adaptaciones más logradas a partir de un cómic. Davis se centra en el caballero de la triste figura por medio de un cuidado dibujo y un exhaustivo trabajo de investigación sobre la obra y la vida de Cervantes. Este cómic busca recrear la atmósfera del original. Una tercera opción, la más reciente en cuanto a su publicación, es Cervantes: la ensoñación de un genio (2015), aquí el dibujante y guionista Miguel Gómez Andrea, conocido con el seudónimo de Gol, presenta una biografía de Cervantes que recupera los gestos de teatralidad del Siglo de Oro y los introduce en las viñetas. Se aborda, además, el proceso de creación del Quijote,

${ }^{10}$ Avances y resúmenes de las tres obras en http://www.dibbuks.es/es/catalogo/don-quijote 
por lo que la obra nos permite indagar en una nueva perspectiva de análisis.

Las tres historietas pueden trabajarse de modo individual o conjunto. Una de las opciones es que luego de la lectura de un capítulo se visualicen las adaptaciones y se contrasten no solamente con el original, sino que también se indague en el propósito de cada ilustrador y en las innumerables posibilidades que arroja la obra de Cervantes, hecho que, reafirma su condición de clásico. Otra opción de trabajo, si el ritmo del curso lo permite, es que los alumnos realicen su propio cómic. El proceso de creación puede partir tanto de la ilustración de los capítulos estudiados en clase como de una adaptación temática que incluya los problemas de la sociedad actual.

Actividad 8. Todos los niveles.

Otro recurso diseñado por el Centro Virtual Cervantes es Ilustrado Don Quijote ${ }^{11}$, aquí se reproduce una ilustración y un fragmento por cada capítulo. Están recogidos los 52 capítulos de la Primera Parte y los 74 de la Segunda. De este modo, puede realizarse un comprimido recorrido por toda la novela. Una propuesta para el aula es que cada alumno lea un capítulo designado por el profesor y explique la frase y la ilustración que lo acompaña, ya sea de manera escrita u oral.

Actividad 9. Nivel: B2, C1, C2.

Visualización del capítulo 11 de la serie El ministerio del tiempo ${ }^{12}$. El visionado se recomienda con subtítulos en español. Este episodio pone en relieve la importancia del Quijote en la historia de la literatura, también muestra diferentes facetas de Cervantes y la relación con otros escritores de la época, como es el caso de Lope de Vega.

Actividad 10. Nivel: B2, C1, C2.

El visionado de las obras teatrales de la compañía Ron Lalá: En un lugar del Quijote ${ }^{13}$ (2013) y La cervantina (2016). Ambas puestas en escena cuentan con la colaboración de la Compañía Nacional de Teatro Clásico. Asimismo, en las dos se puede apreciar la intemporalidad de la obra de Cervantes, la propuesta es «Un viaje del XVII al XXI a lomos de Rocinante». Los guiones recuperan diferentes textos de Cervantes en su aspecto más renovador, también dan cuenta del proceso de escritura del autor y de datos biográficos. Por otro lado, se trae a escena un Cervantes crítico con la España del Siglo de Oro, aspecto que aprovecha Ron Lalá para hacer una sátira de la sociedad del siglo XXI. Cabe destacar que se trata de una reelaboración muy cuidada tanto en la actuación como en la selección de textos, además de que se hace eco de un gran sentido del humor e incorpora a las tablas música en vivo.

No se recomienda la visualización entera de la obra, sino solamente el visionado de

\footnotetext{
11 Disponible en http://cvc.cervantes.es/actcult/quijote_ilustrado/default.htm. Para más opciones ir a http://cvc.cervantes.es/quijote/ [Consulta: 03/05/2017].

12 El capítulo se encuentra en http://www.rtve.es/alacarta/videos/el-ministerio-del-tiempo/capitulo-11tiempo-hidalgos-cervantes-lope-vega-quijote/3505339/ [Consulta: 03/05/2017].

13 Representación completa en https://www.youtube.com/watch? $\mathrm{v}=\mathrm{T} 61 \mathrm{VM} 4 \mathrm{NtrXE}$ [Recuperado 03/05/2017].
} 
algunos fragmentos seleccionados por el docente. La metodología sería estudiar en clase uno de los capítulos y luego visualizar los minutos que la representación dedica a ese capítulo. Las preguntas para trabajar en clase luego de leer y ver cada fragmento estarán destinadas a que los alumnos discutan sobre la puesta en escena, el vestuario y los cambios en el texto y cómo estos aspectos influyen en la reelaboración que la compañía Ron Lalá hace del clásico. Por otro lado, entre los vídeos promocionales de La cervantina se realizó «Cervantes es de todo el mundo» ${ }^{14}$, en el que se recitan fragmentos de su obra desde diversos puntos del planeta y en diferentes idiomas. El trabajo con este spot puede ser una aproximación más sencilla para los niveles iniciales.

\section{El testamento de don Quijote}

Alonso Quijano el Bueno no solo dejó testamento a sus amigos de ficción, nos legó a todos una historia imperecedera que tiene la capacidad de transformarse y seguir llegando a los lectores de todas las épocas. Por ello, son muchas las opciones que quedan, algunas de ellas ya han sido abordadas en otros sitios (Jiménez, 2013), otras serán desarrolladas en próximos trabajos y otras se dejan a criterio de cada docente. Para concluir, el deseo final es que la enseñanza de la obra de Cervantes no se convierta en un molino de viento para los/as profesores/as de E/LE, sino que, como Quijote transformaba las ventas en castillos nosotros podamos transmutar nuestras clases en una oportunidad para el encuentro de los alumnos con ese patrimonio cultural único e insustituible que son los clásicos españoles.

\section{Bibliografía}

Alonso, M. (2012). El cómic en la clase de ELE: una propuesta didáctica. TFM. Recuperado de http://marcoele.com/descargas/14/alonso-comic.pdf

BARRERO, M. (2002). Los cómics como herramientas pedagógicas en el aula. Recuperado el 10/04/2017 de https://www.tebeosfera.com/1/Hecho/Festival/Jerez/ConferenciaJerez020223.pdf

Battagliero Bocco, F. (2016). "Quino y la dislexia en clase de ELE». Foro de Profesores de E/LE. Recuperado el 23/04/2017, de https://ojs.uv.es/index.php/foroele/article/view/9162

Burgos Segarra, G. (2016). «María y yo. El autismo en las aulas a través del cómic». En Lluch, J.; Martínez, J.; Souto, L. (eds.). Las batallas del cómic. Perspectivas sobre la narrativa gráfica contemporánea. Valencia: Colección Anejos, 1, Diablotexto Digital, (pp. 50-66). Recuperado el 03/05/2017 de http://www.uv.es/diabltxd/Anejo1DTD.pdf

Calvino, I. (1992). Por qué leer los clásicos. Barcelona: Tusquets.

CAtalá CARrasco, J. (2007). «El cómic en la enseñanza del español como lengua extranjera». Foro de Profesores de E/LE, vol. 3, pp. 23-32. Recuperado el 20/04/2017 de https://ojs.uv.es/index.php/foroele/article/view/6498/6285

Gamerro, C. (2010). Ficciones barrocas. Buenos Aires: Eterna Cadencia.

García Martínez, I. (2013). El cómic como recurso didáctico en el aula de español

\footnotetext{
${ }^{14}$ Disponible en https://www.youtube.com/watch?v=UmqYdCXl1IU [Recuperado 03/05/2017].
} 
como lengua extranjera. Trabajo de Fin de Máster. Universidad de Cantabria. Recuperado el 03/05/2017 de http://www.mecd.gob.es/dam/jcr:995b00c3-4cd8-41659b49-3df4e0f8bd07/2014-bv-15-02migarciamartinez-pdf.pdf

GonzÁlez Cobas, J.; Herrero Sanz, E. (2009). «El Quijote en la clase de ELE: una propuesta didáctica». Espéculo. Revista de estudios literarios, XIV, vol. 42. Recuperado el 20/04/2017 de https://pendientedemigracion.ucm.es/info/especulo/numero42/ quiele.html

GRACIA, E. (2005). «El Quijote en el aula Crisol didáctico para el encuentro de la lengua, la cultura y el discurso». Recuperado el 30/08/2017 de https://cvc.cervantes.es/ensenanza/quijote_aula/default.htm

Hart, P. (1987). The Spanish Sleuth. The Detective in Spanish Fiction. Cranbury: Associated University Presses.

JimÉnEZ DE Cisneros, C. (2013). «¿Molinos o gigantes? Dramatización de un episodio del Quijote». En Jiménez de Cisneros, C. Del aula al teatro, del teatro al aula. Dramatizaciones para la clase de ELE (pp. 31-33). Marruecos: Ministerio de Educación, Cultura y Deporte.

Maestro, J. G. (2001). «Cide Hamete Benengeli y los narradores del Quijote». En Sánchez, Jean Pierre. Lectures d'une oeuvre. Don Quichotte de Cervantes (pp. 96-127). Paris: Editions du Temps.

Martín, A. (2004). «Los cómics de El Quijote en España, en el cuarto centenario». Cuadernos de Literatura Infantil y Juvenil, vol. 177, 45-55. Recuperado el 20/04/2017 de http://www.tebeosfera.com/1/Documento/Recorte/CLIJ/LosComics/deElQuijote.htm

SEBASTIÁN-FABUEL, V. (2016). «El uso del cómic y la narrativa gráfica como estrategia didáctica en el aula de historia y ciencias sociales». En Lluch, J.; Martínez, J.; Souto, L. (eds.). Las batallas del cómic. Perspectivas sobre la narrativa gráfica contemporánea. Valencia: Colección Anejos, 1, Diablotexto Digital, (pp. 299-318). Recuperado el 18/04/2017 de http://www.uv.es/diabltxd/Anejo1DTD.pdf

Silva-DíAz, M. C. (2009). «Entre el texto y la imagen: Álbumes y otros libros ilustrados». En Teresa Colomer (ed.). Lecturas adolescentes (pp. 151-168). Barcelona: Graó.

Villarrubia ZúÑiga, M. (2009). "Crear un cómic en el aula de ELE». Actas de las II Jornadas Didácticas del IC de Manchester. Recuperado el 20/04/2017 de http://cvc.cervantes.es/ensenanza/biblioteca_ele/publicaciones_centros/PDF/manchester _2009/12_villarrubia.pdf 